\title{
Free to choose? Economic freedom, relative income, and life control perceptions
}

\author{
Hans Pitlik • Martin Rode
}

\begin{abstract}
Recent research has shown that the degree to which people feel they are in control of their lives is an important correlate of individual happiness, where those who feel more in control are found to be systematically happier. In turn, the economic sources of perceived life control are only insignificantly established in the literature. The present paper employs individual data from the World Value Survey and European Values Study, covering the period from 1981 to 2013, to establish the macro-determinants of individual life control. We find that living in a country with high overall economic freedom is a major determinant of feeling in control of one's own life. The effect is similar for individuals in high- and low-income countries, while the impact of democracy is negligible in both cases. Interacting relative income with economic freedom, we find that, contrary to conventional wisdom, it is by far the lower income groups that derive the biggest gain of perceived life control from living in a country with comparatively high economic freedom. In low-income countries, the effects of economic freedom on life control perceptions do not appear to be conditional on personal income levels.
\end{abstract}

Keywords: Locus of control, economic institutions, well-being, democracy

\section{Introduction}

The search for the determinants of happiness (or life satisfaction) has grown in intensity in recent years. Innumerable articles based on multidisciplinary research have produced a whole array of individual and social correlates of "the good life". These range from individual life circumstances, like personal income, employment, or health status, through traits like interpersonal trust, all the way to macro-determinants at the country-level, such as GDP per capita, democracy, and the quality of economic institutions. ${ }^{1}$

Recently, a number of articles have also found that the degree to which people feel they are in control of their own lives is an important correlate of subjective wellbeing measures (e.g. Inglehart et al. 2008, Verme 2009, Bavetta and Navarra 2011). According to this literature, people who perceive they are comparatively more in control of their own fate are also found to be systematically happier as individuals. This enhanced feeling of life control could just be the product of personality characteristics, or also the outcome of changing economic and social circumstances that increase freedom of choice for the individual. The latter has been argued by Inglehart et al. (2008), who identify enhanced life satisfaction and control with greater individual freedom. However, from the perspectives of social psychology and consumer research, the relationship between enhanced freedom of choice and wellbeing is not so clear-cut: Schwartz (2000 and 2004), for example, argues that freedom of choice may be detrimental to individual

${ }^{1}$ Reviews by Dolan et al. (2008) or Frey (2008) provide good overviews of the topic. 
well-being, as it involves high information and decision-making costs. Hence, a choice-induced paralysis may be a sign of a "Tyranny of Freedom", where people are not able to cope with the perceived oversupply of different choices available to them.

The concept of locus of control, originally developed by Rotter (1966), refers to the degree to which individuals expect outcomes to be contingent on their own behavior or personal characteristics, versus the degree to which they expect outcomes to be a function of pure chance or fate. Individuals who perceive themselves as having a high internal locus of control believe in their own ability to control life's course and influence the world around them. They interpret personal choices as the main cause of individual success or failure. In contrast, people with a high external locus of control believe that control over events is largely outside their influence. These individuals believe they are under the control of powerful others, or some supernatural being, where the outcome of situations is beyond their sphere of influence.

Compared across different disciplines, the link between locus of control and subjective wellbeing has been studied somewhat more intensely in psychology up to date (e.g. April et al. 2012), where underlying individual characteristics are the main focal point. Recently however, a few papers also treat this relationship from an institutional-economic perspective: For example, Bavetta and Navarra (2011) find that economic freedom and locus of control, defined as autonomy freedom, complement each other in the determination of happiness. Verme (2009) provides a promising application by claiming that locus of control affects how people evaluate freedom of choice. So-called internals believe that they have control of their lives and that outcomes are the consequences of effort and skills. For internals, freedom of choice is therefore a more significant source of happiness than for externals, who feel that they have little or no control over their lives. As Verme (2009) highlights, the degree to which individuals value free choice, a fundamental concept in neoclassical economics, might very well be regulated by the degree to which these same people feel they are in control of their lives.

According to similar arguments forwarded by Buchanan (2005), the demand for big government is associated with a certain fear of freedom and anxiety about being made responsible for one's own actions. So if individuals feel capable of reaping the benefits of free choice and minimal government intervention, they are likely to value both highly and vice versa. In line with these ideas, Kouba and Pitlik (2014) show for a sample of EU and OECD member states that an internal locus of control is strongly related to negative attitudes towards government interventionism.

If we take it as given that individual locus of control is a major determinant of personal life satisfaction and happiness, and that some people might be more able to reap these benefits, the next logical question is to investigate the macro-determinants of life control itself: What are the factors that determine whether people feel largely in control of their lives, or not? Up to date, this question is addressed only insignificantly in the economic literature, even though the psychic capacity to make choices and assume their consequences is known to be vital for the existence of a market economy (c.f. Buchanan 2005, Verme 2009).

Notable exceptions are Inglehart et al. (2008) and Welzel (2014). Both studies draw on lifestyle changes during the past thirty years to explain the perceived increase in life control, finding that these may be driven by economic development, democratization, and increased tolerance. Still, these authors have neglected a possible connection between locus of control and economic freedom. Following Buchanan (2005), we do this in the current paper, recognizing that capitalism and free markets are an important element of individual freedom. In particular, we would like to find out if economic institutions that are built on the principle of freedom of choice are also drivers of individual life control perceptions. 
It is almost surprising that this question has not been investigated earlier, because a variety of papers have found determinants of life satisfaction and other personality traits to be significantly influenced by economic institutions. For instance, Berggren and Jordahl (2006) find support for the idea that market economies, which are built on voluntary transactions with both friends and strangers and within the predictability provided by the rule of law, entail incentives for social trust to emerge. Similarly, Berggren and Nilsson (2013) find that the degree to which economic institutions and policies are market-oriented is related to tolerance. They find economic freedom to be positively related to tolerance towards homosexuals, especially in the longer run, while tolerance towards people of a different race and a willingness to teach children tolerance are not strongly affected.

In addition, a large number of studies have shown that there is also an effect of economic institutions on happiness. Employing the Economic Freedom of the World (EFW) Index by the Fraser Institute, Ovaska and Takashima (2006), Gehring (2013), and Rode (2013) find economic freedom to be an important determinant of happiness or life satisfaction. Taking into account that all these authors omit the question of locus of control in their models, it might just as well be the case that the effect of economic freedom on subjective wellbeing passes through the feeling of being in control of one's own life.

Employing individual data from the latest versions of the World Value Survey and the European Values Study (WVS/EVS), we find that high overall economic freedom is a major determinant of the perception of being in control of one's own life, even if we control for economic development as measured by PPP-adjusted GDP per capita. Interestingly, the effect of economic freedom is similar for individuals in high- and low-income countries, but only as long as we do not control for common shocks to life control perceptions over time. The positive effect of economic freedom on life control remains robust to the inclusion of time dummies in our sample of rich countries, while it becomes insignificant in our sample of poorer countries when time-fixed effects are included. The impact of electoral democracy is negligible in both cases.

We further test a widespread belief stating that economic freedom benefits primarily people at the top of the income distribution. In terms of life control, the effects are not so clear-cut however, as high-income earners generally enjoy freedom of choice, whereas those at the bottom of the income distribution may be 'double-constrained' by low income and restricted opportunities. At the individual level, our results imply that a high personal income rank also has a substantial positive impact on the perceived control over one's own life, reflecting the fact that a higher income generally gives people more freedom to decide their life's own course. The effect of income rank on individual life control also appears to be stronger in low-income countries, as compared to richer countries. Interacting income rank with economic freedom, we find that it is also the groups at the bottom of the income distribution that derive by far the biggest life control gains from living in a country with comparatively high economic freedom. Closer inspection again reveals that this effect is primarily driven by the rich-country sample. We thus conclude that the strong relationship between economic freedom at relatively low income levels and life control is likely to be driven by reduced individual choice restrictions for the inhabitants of wealthy countries only. In turn, perceiving a low relative income in a poor country cannot be compensated for by increased opportunities, highlighting the elevated degree of restrictions that poverty imposes on individuals' freedom of choice.

The remainder of the paper is organized as follows: Section two focuses on the description of the data and the research strategy of our analysis. Section three presents a graphical analysis, the empirical estimations, and discusses the results. Section four concludes. 


\section{Data and research strategy}

This paper employs data from the European Values Study and the World Values Survey (2014) to measure internal locus of control and other individual characteristics of respondents. These organizations have interviewed different people in a large number of countries in a series of six waves since the early 1980s, employing a similar methodology throughout all waves. Generally, the surveys are all conducted for a representative sample of the adult population of each country, and the resulting data is freely available to all users.

We use the integrated data file that includes longitudinal aggregates from all six waves of the EVS/WVS, covering the period between 1981 and 2014. In particular, perception of life control is based on the following survey question: "Some people feel they have completely free choice and control over their lives, while other people feel that what they do has no real effect on what happens to them. Please use this scale [...] to indicate how much freedom of choice and control you feel you have over the way your life turns out." Respondents answer on a ten-point scale, ranging from "none at all" (1) to "a great deal" (10). This survey question captures the notion of external versus internal locus of control almost perfectly.

Economic institutions are measured by the Economic Freedom of the World (EFW) Index (Gwartney et al., 2014). This index is published annually by the Canadian Fraser Institute and includes 43 specific components, all measured on a zero to ten scale, reflecting the degree to which the economic institutions and policies of a country correspond to free market principles. A ' 0 ' represents the least free and a '10' the most free. While the EFW index now covers 141 countries, the data for the compound index and the individual areas are available for approximately 100 countries at five-year intervals between 1980 and 2000, and annually since the year 2000.

The EFW Index has been used extensively in social science research in recent years. It is based entirely on data published in secondary sources, which means it can be easily verified and duplicated by others (Berggren 2003). This transparency feature adds to its credibility. The indicator has been related to a number of other important economic variables, such as overall income levels and growth (Pitlik 2002, de Haan et al. 2006, Doucouliagos and Ulubasoglu 2006, Rode and Coll 2012), inequality (Berggren 1999, Bennett and Nikolaev 2015), political democracy (Rode and Gwartney 2012), and subjective wellbeing (Rode 2013). The summary EFW Index is nowadays divided into five major areas:

1) Size of government: Expenditure, taxes, and enterprises,

2) Legal structure and security of property rights,

3) Access to sound money,

4) Freedom to trade internationally,

5) Regulation of credit, labor, and business.

The summary score for each country is calculated by simply taking the mean of the ratings in each of the five areas.

To test our hypotheses, we perform pooled Ordinary Least Squares (OLS) ${ }^{2}$ regressions of personal life control on the level of economic freedom, individual income rank (and an interaction of both terms), introducing a range of individual-level controls, country-level controls and country fixed effects to account for unobserved heterogeneity. To account for the Moulton-

\footnotetext{
${ }^{2}$ Alternatively, the model can be estimated with ordered probit, which gives us very similar results. Since OLS estimations are generally easier to interpret though, we only report the results of our OLS fixed effects estimates. The ordered probit results are available upon request.
} 
bias that causes the standard errors of macro-covariates to be far too small and which is inherent in such a survey data setting (Moulton 1990), we corrected for clustering on the country level.

EFW variables are chosen to be from the year before the actual survey was conducted. If data for a particular year was not available, we used linear interpolation to arrive at a hypothetical score. Such a procedure is only relevant for the 1980s and 1990s, where EFW-data is available only at five-year intervals. Formally, in our baseline specification we model life control perceptions of individual $i$ living in country $j$ at time $t$, as follows:

(1) lifecontrol $_{\mathrm{ijt}}=\beta_{0}+\beta_{1}$ incomerank $_{\mathrm{ijt}}+\beta_{2} \mathrm{EFW}_{\mathrm{jt}}+\beta_{4}$ individualcontrols $_{\mathrm{ijt}}+$ $\beta_{5}$ macrocontrols $_{j \mathrm{t}}+\mathrm{cfe}_{\mathrm{j}}+\mathrm{tfe}_{\mathrm{t}}+\varepsilon_{\mathrm{i}}$,

Individual income rank is the self-reported income decile, from the WVS/EVS database. We expect it to be positively related to life control, because a higher relative income generally gives people more freedom to follow their own life course, while people with lower relative incomes should feel much more restricted by their economic circumstances.

Further controls include a full array of individual characteristics, which supposedly impact on personal life control perceptions apart from income. All variables are from the WVS/EVS database. We include the following:

- Social trust: trust in other people is expected to be associated positively with life control perceptions, as the degree of social trust seems to capture the quality of informal institutions and social capital in a society (e.g. Bjørnskov 2003). Due to the strong influence of societal structures in the formation of social capital, individuals with higher social trust should therefore also report higher perceived life control, reflecting the underlying informal arrangements of a society.

- Religiosity: a religious person who strongly believes in a 'divine being' may be assumed to have less individual control of her/his own life; however, one may also expect religious people to have a higher confidence in their ability to influence life course if they trust in the backing and help of a higher authority.

- Health: a good health status is expected to be associated positively with the perception of control over one's own life, as compared to subjectively perceived bad health.

- Employment: self-employed people may find themselves in a position to have more control over their own life course; being unemployed, on the other hand, may be expected to be associated with a reduced perceived life control. In addition, people with a fulltime job may find themselves better able to control their lives regardless of their income.

- Age: a person's age may also play an important role for his/her life control perception. This effect is probably u-shaped, with younger and older people tending to believe that they control life course, while 'middle-aged' people 'in the treadmills of everyday life' may feel less in control. To account for such an effect, we include dummy variables for age 15-30 and over 60, while the age group between 30 and 60 serves as a reference group.

- Gender: the roles of men and women are known to be very different in different societies across the world, plausibly influencing life control perceptions to a large degree. In our estimations, we control for this fact with a female dummy.

In addition to individual controls, we introduce country-wide covariates: the (log of) real Gross Domestic Product (GDPPC) per capita (lagged one year, PPP adjusted US-Dollar in logs, from 
the Penn World Tables 8.1) ${ }^{3}$ and the Freedom House 2014 political democracy index (DEMPOL) which coincides with the respective survey year. ${ }^{4}$ Country fixed effects ( $c f e$ ) capture unobserved heterogeneity and cultural differences that drive the subjective perception of one's own life control. The respective fixed effects are not explicitly calculated, but absorbed, which is a suitable strategy that is especially designed for datasets with many groups, but not a number that grows with the sample size. In order to further account for unobserved common shocks that jointly affect individual values in all countries, we employ time period dummies tfe for 1980-89, 199099, and 2000-2009 (2010-14 being the reference period). Note, however, that $t f e$ may substantially absorb effects of over-time changes in our macro-variables EFW, GDPPC, and DEMPOL. As a consequence, we decided to report results with, and without, time period effects.

In the second specification we add an interaction term of income rank and economic freedom to account for life control effects of economic freedom conditional on relative income position:

(2) lifecontrol $_{\mathrm{ijt}}=\beta_{0}+\beta_{1}$ incomerank $_{\mathrm{ijt}}+\beta_{2} \mathrm{EFW}_{\mathrm{jt}}+\beta_{3}\left(\right.$ incomerank $\left._{\mathrm{ijt}} \times \mathrm{EFW}_{\mathrm{jt}}\right)+$ $\beta_{4}$ individualcontrols $_{\mathrm{ijt}}+\beta_{5}$ macrocontrols $_{\mathrm{jt}}+\mathrm{cfe}_{\mathrm{j}}+\mathrm{tfe}_{\mathrm{t}}+\varepsilon_{\mathrm{i}}$,

The underlying logic for the interaction term is that economic freedom should have a very diverse life control impact for people with different incomes. Especially for people of a relatively low income, we expect economic freedom levels to make a major difference for life control, because greater market opportunities should also give them an enhanced feeling of being in control of their destiny. Therefore, a more liberalized economy does not automatically contribute to life control perceptions of the rich. On the contrary, increased choice and opportunities probably strengthens the life control of poor people more than that of richer people. High-income earners are possibly even more constrained in a competitive setting, while people at the lower end of the income distribution may still be constrained by their smaller incomes, but not by restricted opportunities.

Descriptive statistics of all variables in our sample can be found in Table A1 in the appendix. Total sample size covers responses from 262,960 individuals in 76 countries. Due to the fact that a number of countries were repeatedly surveyed in the WVS, the actual number of country-level observations in our dataset is 183 . The sample mean of the life control variable is 6.9 , with a standard deviation of 2.3; the sample mean of the EFW summary index is 6.75, with a standard deviation of 1.1.

To illustrate the positive relationship between average life control and economic freedom scores, Figure 1 below shows a simple scatterplot of both variables at the country level, where the EFW Index is lagged by one year. The resulting graphical association strongly supports our basic idea of a positive relationship between economic freedom and life control. However, the direction of causality is far from clear at the aggregate country level: Does economic freedom cause higher life control, or does a higher (average) life control perception lead to increased political support for economic freedom? Findings by Kouba and Pitlik (2014) suggest the latter, since individuals with higher life control also support less government interventionism. But while this problem of reverse causality cannot be ruled out in any macro-level analysis, it is a much less severe issue at the individual level. Here, overall economic freedom levels may surely have an effect on the personal perception of life control, but the impact of a single individual's life control perception on country-wide economic freedom policies is marginal, at best (we

\footnotetext{
${ }^{3}$ As PWT data for 2012 are not yet available, we used real GDP per capita growth rates for that year from the World Development Indicators to calculate the GDP per capita level in 2012.

${ }^{4}$ We re-coded the political democracy scale to a 0-10 scale, where higher scores also represent more democratic societies.
} 
assume that dictators do not take part in the surveys). Therefore, we opted for estimating the effects at the individual level, which also gives us the possibility to make a tentative statement on the direction of causality. Results are presented in the next section.

Figure 1. Life control and economic freedom at the country level

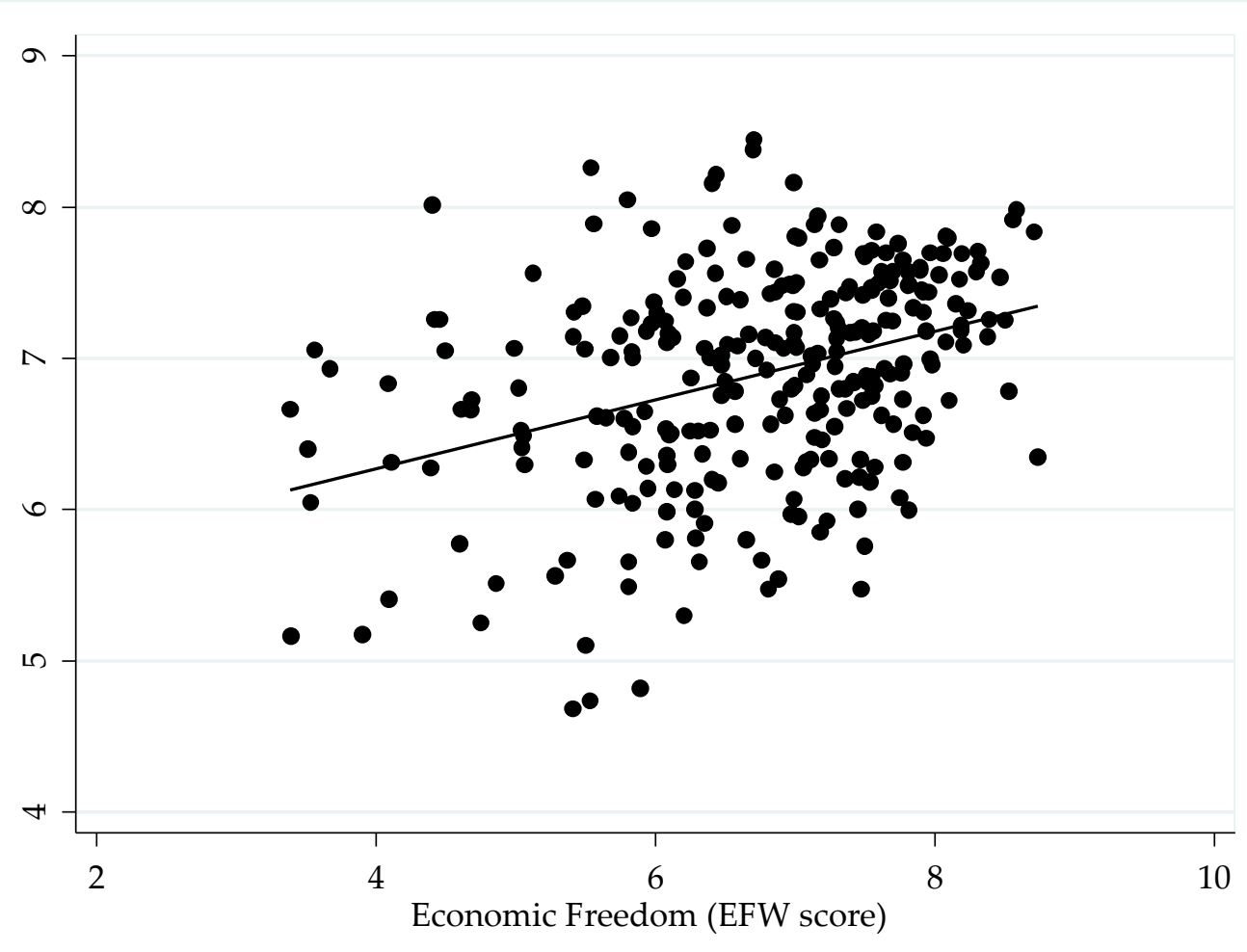

\section{Results}

\subsection{Baseline estimates}

Results of our baseline OLS fixed effects regressions are displayed in Table 1 below, where we also present the full set of individual control variables. Columns (1) to (5) show estimates for the entire sample of 76 countries, based on more than 260,000 single observations.

We start in equation (1) with a parsimonious specification, including only income rank, lagged economic freedom (EFW), and country fixed effects. In line with our expectations, EFW has a positive coefficient $(+0.26)$ and is statistically significant at the $1 \%$ level. Individual income rank is positive $(+0.12)$ and highly significant. The size of the coefficients indicates that a 1-point increase of the EFW index has an impact on life control that is comparable to an upward leap of roughly two deciles on the personal income ladder. This is a sizable effect, highlighting the potential outcome for life control perceptions of a comparatively more liberalized economy.

Equation (2) adds the full set of individual covariates. Coefficients for EFW and income rank are slightly smaller, but remain highly significant. The individual control variables behave as expected. In particular, a good health status is strongly and positively related to perceived life control. Trusting other, unknown, people, religiousness, being self-employed, having a fulltime job and not being unemployed are also associated positively with life control perceptions. We also find the expected $\mathrm{u}$-shape effect of age on life control, while women on average appear to have a slightly lower life control perceptions. 
Table 1a: Impact of economic freedom and income rank on life control perceptions

\begin{tabular}{|c|c|c|c|c|c|c|c|c|c|c|c|}
\hline Sample & $\begin{array}{c}1 \\
\text { full }\end{array}$ & $\begin{array}{c}2 \\
\text { full }\end{array}$ & $\begin{array}{c}3 \\
\text { full }\end{array}$ & $\begin{array}{c}4 \\
\text { full }\end{array}$ & $\begin{array}{c}5 \\
\text { full }\end{array}$ & $\begin{array}{c}6 \\
\text { high } \\
\text { income }\end{array}$ & $\begin{array}{c}7 \\
\text { high } \\
\text { income }\end{array}$ & $\begin{array}{c}8 \\
\text { high } \\
\text { income }\end{array}$ & $\begin{array}{c}9 \\
\text { low } \\
\text { income }\end{array}$ & $\begin{array}{c}10 \\
\text { low } \\
\text { income }\end{array}$ & $\begin{array}{c}11 \\
\text { low } \\
\text { income }\end{array}$ \\
\hline \multirow[t]{2}{*}{ EFW } & 0.260 & 0.244 & 0.171 & 0.192 & 0.194 & 0.188 & 0.228 & 0.230 & 0.224 & 0.135 & 0.140 \\
\hline & 0.000 & 0.000 & 0.002 & 0.003 & 0.003 & 0.010 & 0.002 & 0.001 & 0.055 & 0.298 & 0.286 \\
\hline \multirow[t]{2}{*}{ Income rank (decile) } & 0.118 & 0.092 & 0.092 & 0.092 & & 0.061 & 0.063 & & 0.130 & 0.127 & \\
\hline & 0.000 & 0.000 & 0.000 & 0.000 & & 0.000 & 0.000 & & 0.000 & 0.000 & \\
\hline \multirow[t]{2}{*}{ 1st income quintile } & & & & & -0.668 & & & -0.473 & & & -0.947 \\
\hline & & & & & 0.000 & & & 0.000 & & & 0.000 \\
\hline \multirow[t]{2}{*}{ 2nd income quintile } & & & & & -0.453 & & & -0.270 & & & -0.732 \\
\hline & & & & & 0.000 & & & 0.000 & & & 0.000 \\
\hline \multirow[t]{2}{*}{ 3rd income quintile } & & & & & -0.287 & & & -0.164 & & & -0.515 \\
\hline & & & & & 0.000 & & & 0.000 & & & 0.000 \\
\hline \multirow[t]{2}{*}{ 4th income quintile } & & & & & -0.116 & & & -0.063 & & & -0.263 \\
\hline & & & & & 0.000 & & & 0.030 & & & 0.000 \\
\hline \multirow[t]{2}{*}{ Social trust } & & 0.188 & 0.188 & 0.188 & 0.191 & 0.312 & 0.310 & 0.313 & 0.005 & 0.003 & 0.005 \\
\hline & & 0.000 & 0.000 & 0.000 & 0.000 & 0.000 & 0.000 & 0.000 & 0.903 & 0.943 & 0.906 \\
\hline \multirow[t]{2}{*}{ Religiosity } & & 0.084 & 0.095 & 0.094 & 0.092 & 0.085 & 0.089 & 0.089 & 0.092 & 0.100 & 0.098 \\
\hline & & 0.022 & 0.008 & 0.009 & 0.010 & 0.031 & 0.022 & 0.024 & 0.191 & 0.159 & 0.167 \\
\hline \multirow[t]{2}{*}{ Female } & & -0.056 & -0.058 & -0.057 & -0.058 & 0.019 & 0.020 & 0.020 & -0.148 & -0.148 & -0.149 \\
\hline & & 0.019 & 0.015 & 0.015 & 0.014 & 0.457 & 0.447 & 0.448 & 0.000 & 0.000 & 0.000 \\
\hline \multirow[t]{2}{*}{ Age 15-30 } & & 0.085 & 0.092 & 0.091 & 0.090 & 0.202 & 0.207 & 0.205 & -0.018 & -0.015 & -0.014 \\
\hline & & 0.005 & 0.003 & 0.003 & 0.003 & 0.000 & 0.000 & 0.000 & 0.579 & 0.641 & 0.660 \\
\hline \multirow[t]{2}{*}{ Age over 60} & & 0.118 & 0.107 & 0.109 & 0.106 & 0.109 & 0.108 & 0.106 & 0.079 & 0.066 & 0.062 \\
\hline & & 0.002 & 0.006 & 0.005 & 0.005 & 0.012 & 0.013 & 0.014 & 0.282 & 0.357 & 0.393 \\
\hline \multirow[t]{2}{*}{ Good health } & & 0.533 & 0.525 & 0.524 & 0.526 & 0.610 & 0.606 & 0.608 & 0.435 & 0.423 & 0.429 \\
\hline & & 0.000 & 0.000 & 0.000 & 0.000 & 0.000 & 0.000 & 0.000 & 0.000 & 0.000 & 0.000 \\
\hline \multirow[t]{2}{*}{ Self-employed } & & 0.181 & 0.179 & 0.180 & 0.182 & 0.243 & 0.240 & 0.244 & 0.154 & 0.156 & 0.156 \\
\hline & & 0.000 & 0.000 & 0.000 & 0.000 & 0.000 & 0.000 & 0.000 & 0.000 & 0.000 & 0.000 \\
\hline \multirow[t]{2}{*}{ Unemployed } & & -0.171 & -0.173 & -0.175 & -0.177 & -0.360 & -0.363 & -0.364 & -0.039 & -0.038 & -0.044 \\
\hline & & 0.000 & 0.000 & 0.000 & 0.000 & 0.000 & 0.000 & 0.000 & 0.308 & 0.340 & 0.269 \\
\hline \multirow[t]{2}{*}{ Fulltime job } & & 0.110 & 0.111 & 0.112 & 0.115 & 0.058 & 0.057 & 0.059 & 0.166 & 0.173 & 0.176 \\
\hline & & 0.000 & 0.000 & 0.000 & 0.000 & 0.014 & 0.010 & 0.007 & 0.000 & 0.000 & 0.000 \\
\hline \multirow[t]{2}{*}{ GDPPC } & & & & -0.150 & -0.147 & 0.186 & -0.118 & -0.123 & 0.051 & -0.137 & -0.138 \\
\hline & & & & 0.258 & 0.265 & 0.327 & 0.553 & 0.532 & 0.811 & 0.527 & 0.523 \\
\hline
\end{tabular}


Table 1b: Impact of economic freedom and income rank on life control perceptions

\begin{tabular}{|c|c|c|c|c|c|c|c|c|c|c|c|}
\hline Sample & $\begin{array}{c}1 \\
\text { full }\end{array}$ & $\begin{array}{c}2 \\
\text { full }\end{array}$ & $\begin{array}{c}3 \\
\text { full }\end{array}$ & $\begin{array}{c}4 \\
\text { full }\end{array}$ & $\begin{array}{c}5 \\
\text { full }\end{array}$ & $\begin{array}{c}6 \\
\text { high } \\
\text { income }\end{array}$ & $\begin{array}{c}7 \\
\text { high } \\
\text { income }\end{array}$ & $\begin{array}{c}8 \\
\text { high } \\
\text { income }\end{array}$ & $\begin{array}{c}9 \\
\text { low } \\
\text { income }\end{array}$ & $\begin{array}{c}10 \\
\text { low } \\
\text { income }\end{array}$ & $\begin{array}{c}11 \\
\text { low } \\
\text { income }\end{array}$ \\
\hline DEMPOL & & & & $\begin{array}{l}\mathbf{0 . 0 1 8} \\
0.751\end{array}$ & $\begin{array}{l}\mathbf{0 . 0 1 9} \\
0.732\end{array}$ & $\begin{array}{r}-0.045 \\
0.342\end{array}$ & $\begin{array}{r}-0.061 \\
0.234\end{array}$ & $\begin{array}{r}-\mathbf{- 0 . 0 6 0} \\
0.249\end{array}$ & $\begin{array}{l}\mathbf{0 . 0 3 3} \\
0.654\end{array}$ & $\begin{array}{l}\mathbf{0 . 0 2 8} \\
0.689\end{array}$ & $\begin{array}{l}\mathbf{0 . 0 2 9} \\
0.678\end{array}$ \\
\hline Period fixed effects & no & no & yes & yes & yes & no & yes & yes & no & yes & yes \\
\hline Country fixed effects & yes & yes & yes & yes & yes & yes & yes & yes & yes & yes & yes \\
\hline $\mathbf{N}$ & 262960 & 262960 & 262960 & 262960 & 262960 & 139569 & 139569 & 139569 & 123391 & 123391 & 123391 \\
\hline Countries & 76 & 76 & 76 & 76 & 76 & 39 & 39 & 39 & 37 & 37 & 37 \\
\hline Adj. R-square & 0.095 & 0.109 & 0.110 & 0.110 & 0.110 & 0.115 & 0.116 & 0.115 & 0.110 & 0.111 & 0.111 \\
\hline F-stat (model) & 76.8 & 100.6 & 78.3 & 71.7 & 71.0 & 68.1 & 100.0 & 127.5 & 69.2 & 71.6 & 67.0 \\
\hline
\end{tabular}


In equation (3) we add the time period dummy variables. The indicators are significant and show that life control has increased over time (not reported). While inclusion of time dummies does not affect the individual controls, the coefficient of EFW is reduced to +0.17 but remains significant. In equation (4) we add the logarithm of lagged GDP per capita (GDPPC), and contemporary democracy (DEMPOL). Political democracy is positive but far from any conventional significance level. GDPPC is negatively related to individual life control, but insignificant. EFW remains positive and significant. This result may be influenced by collinearity of EFW, GDPPC, and DEMPOL. Surprisingly, dropping EFW from the set of explanatory variables does not lead to the expected positive relationship of GDPPC to life control perceptions. Only when we also drop the time period dummies does GDPPC show a positive and significant relation to our dependent variable.

Our democracy measure DEMPOL always remains insignificant. ${ }^{5}$ We checked this result by employing different democracy indicators, including Polity IV scores, the DemocracyDictatorship dataset, or the World Banks' Good Governance Indicators. In all cases, democracy is positively related to life control perceptions, but is insignificant in most cases, and the different indicators always lose significance when we control for economic freedom.

Finally, in equation (5) we replaced our individual income deciles by categorical income quintiles, the 5th income quintile serving as reference group. The coefficients indicate a small non-linear effect of income rank: Households in the 4th income quintile still report a lower life control perception than the ones from the highest quintile. However, the difference is only 0.1, while for lower-ranked incomes an upward move of one step to the higher quintile increases life control perceptions by roughly 0.2 points. This also helps us to interpret the effects of higher economic freedom: A one-point increase of the EFW index, which amounts to roughly one standard deviation, increases life control by +0.2 points.

To account for the effects of economic development in our analysis, we further divided our dataset into two subsamples of almost equal size. Columns (6) to (8) report the results for a sample of 39 rich OECD and EU countries, including also Taiwan and Singapore. The rest of the world sample, shown in columns (9) to (11), contains 37 less developed countries from around the globe, including some of the more recent OECD members, such as Turkey, Mexico, and Chile. Both subsamples are specified in Table A2 of the appendix.

In the rich-country sample, the effect of EFW is positive (6) and remains significant if we include time period dummies (in equations (7) and (8)); the coefficient of EFW even increases when time dummies are added. In the poor-country sample, however, the positive effect of EFW on life control is weakened and even becomes statistically insignificant if time period controls are included (equations (9) and (10)). As mentioned earlier in the text, the inclusion of time dummies might actually be a somewhat excessive robustness test, because it filters out some of the underlying reasons for common variations in life control perceptions over time. As Gwartney et al. (2014) also highlight, economic freedom has increased on a worldwide scale since the early 1990s, but it is especially the group of countries that we include in our poor-country sample that have made the most significant strides towards more liberalized economies since then. This parallel move is probably what is now being captured by our time dummies in equations (9) to (11), tentatively explaining the loss of statistical significance for explaining varying levels of life control.

\footnotetext{
5 These results are also robust with regard to the estimation method employed. Random-slope multilevel regressions (available upon request) confirm our findings in almost every detail.
} 
The sample split in Table 1 also offers some interesting insights when considering individuallevel covariates. In the full sample, the effect of moving one step up on the income ladder for individual life control is on average +0.1 across all income groups. So having a smaller relative income has a negative impact on life control. We also observe that the impact of an increase in relative income is substantially stronger in the poor-country sample than in the rich-country sample. Income rank appears to be more important for individual life control perceptions in less developed countries and this may point to a different valuation of relative incomes in both subsamples. Intuitively, one can also imagine that income rank will have a much stronger impact on the feeling of overall life control if the individual lives in a less affluent society. Having a low income in a poor country means that there is not a whole lot of opportunity to influence the way your life turns out, as compared to having a low income in a rich country. These findings highlight the massive individual restrictions that are created by poverty in the developing world.

Alternatively, having a full time job or being self-employed is positively related to individual perceptions of life control in both subsamples. Unemployment is a strong predictor of reduced life control, but interestingly this effect is present only in the rich country sample. Both younger (below the age of 30) and older (above the age of 60) individuals report having a higher life control than the group of 30-59 years old. However, this association is encountered in the highincome country sample only. A self-reported good, or very good, health status is strongly related to life control $(+0.5)$ in all samples, but the effect is stronger in the rich-country sample. Notably, gender does not play a significant role for life control in the rich-country sample, while in the poor-country sample the perceived life control of women is significantly lower ( -0.15 points) than that of men. Religiousness is only weakly related to life control $(+0.1)$ and this is only the case for individuals living in developed countries.

A further interesting finding is made in the case of interpersonal trust: in the overall sample, respondents who state that they generally trust other anonymous people also have a higher perception of life control. But we find that this effect is exclusively driven by responses from the rich-country sample, while the relationship between social trust and perceived life control disappears in the poor-country sample. One tentative explanation for this finding is that average social trust is overall much lower in our poor-country sample. If social trust is generally absent in a society, it doesn't provide the individual that happens to be trusting with a sensation of higher life control anymore. So a sufficient amount of people in a society probably need to trust in others, in order for the trusting individual to gain some type of life control from this personal trait. ${ }^{6}$

\subsection{Who gains the most life control from economic freedom?}

A widespread common belief is that economic freedom primarily benefits people at the top of the income distribution. Policies that increase economic freedom in a certain country are often perceived to be a program for big business that pays off only for the already rich and powerful. For example, Bergh and Nilsson (2010) claim that economic freedom may increase income equality in richer countries. Using US state-level data, Compton et al. (2014) recently showed that

\footnotetext{
${ }^{6}$ Controlling for the country average of social trust shows that social trust is not significant in the rich-country sample but is strongly negatively related to life control in the poor-country sample. We also checked whether perceptions and personal ideological position are related and found that (self-assessed) political right-wingers generally report a higher average life control (not shown). As a consequence, we did not follow this route any further, as this would create a severe causality question for our investigation: Do political right-wingers perceive more life control, or are people with higher life control perceptions more likely to become political right-wingers? What is important in this context is the fact that all our results are unaffected by the inclusion of a political ideology variable.
} 
increases in economic freedom positively contribute to income growth. However, the benefits are not equally distributed across the population. In particular, they find that higher income quintiles tend to enjoy higher rates of income growth as a consequence of more economic freedom, and that this positive effect generally does not extend to the lowest income groups.

From a life control perspective this effect is, however, not so obvious. We have already seen that higher income groups experience more overall individual life control, regardless of the degree of economic freedom that is present in a country. Therefore, a more liberalized economy, which is characterized by increased freedom of choice and competition for all, does not automatically contribute to life control perceptions of the rich. On the contrary, increased choice and opportunities may comparatively strengthen life control perceptions of relatively poor people more than that of relatively rich people. High-income earners are more constrained in a competitive setting than in an institutional environment with state-granted privileges, while people at the lower end of the income distribution may be constrained by their smaller incomes but not at the same time by restricted opportunities. To test for a possible asymmetrical effect of economic freedom on life control perceptions, conditional on relative income levels, we added to our estimations an interaction term of the income rank with the EFW index score. All macro controls and individual controls are included (not shown). Results are shown in Table 2 below.

Table 2: Effect of economic freedom on life control, conditional on income rank

\begin{tabular}{|c|c|c|c|c|c|c|}
\hline Sample & $\begin{array}{c}1 \\
\text { full }\end{array}$ & $\begin{array}{c}2 \\
\text { full }\end{array}$ & $\begin{array}{c}3 \\
\text { high } \\
\text { income }\end{array}$ & $\begin{array}{c}4 \\
\text { high } \\
\text { income }\end{array}$ & $\begin{array}{c}5 \\
\text { low } \\
\text { income }\end{array}$ & $\begin{array}{c}6 \\
\text { low } \\
\text { income }\end{array}$ \\
\hline \multirow[t]{2}{*}{$\overline{E F W}$} & 0.310 & 0.298 & 0.275 & 0.306 & 0.285 & 0.199 \\
\hline & 0.000 & 0.000 & 0.001 & 0.000 & 0.021 & 0.128 \\
\hline \multirow[t]{2}{*}{ Income rank (decile) } & 0.278 & 0.268 & 0.203 & 0.199 & 0.232 & 0.233 \\
\hline & 0.000 & 0.000 & 0.002 & 0.001 & 0.002 & 0.001 \\
\hline \multirow[t]{2}{*}{$\mathrm{EFW}^{*}$ income rank } & -0.027 & -0.026 & -0.020 & -0.019 & -0.016 & -0.017 \\
\hline & 0.000 & 0.000 & 0.016 & 0.010 & 0.115 & 0.087 \\
\hline Period fixed effects & no & yes & no & yes & no & yes \\
\hline Country fixed effects & yes & yes & yes & yes & yes & yes \\
\hline $\mathrm{N}$ & 262960 & 262960 & 139569 & 139569 & 123391 & 123391 \\
\hline Countries & 76 & 76 & 39 & 39 & 37 & 37 \\
\hline Adj. R-square & 0.110 & 0.111 & 0.115 & 0.116 & 0.110 & 0.111 \\
\hline F-stat (model) & 83.3 & 70.7 & 65.5 & 97.3 & 64.3 & 65.6 \\
\hline
\end{tabular}

Note: OLS-fixed effects regressions with standard errors clustered at the country level. P-values shown beneath bold typed coefficients. Constant not reported. Additional control variables see Table 1.

Columns (1) and (2) report results for the full sample, including the interaction of individual income rank assessment and the average country EFW index score. In the first columns time period effects are not included, but they are added in equation (2). Results, however, are very similar. We find a negative and significant interaction effect, which is in line with the notion that higher levels of economic freedom benefit lower income groups relatively more, when compared to higher income groups. For the full sample, Figure 2 below further illustrates the marginal effects of increases in economic freedom on perceived life control, conditional on income rank. 
Figure 2: Marginal effect of economic freedom (full sample)

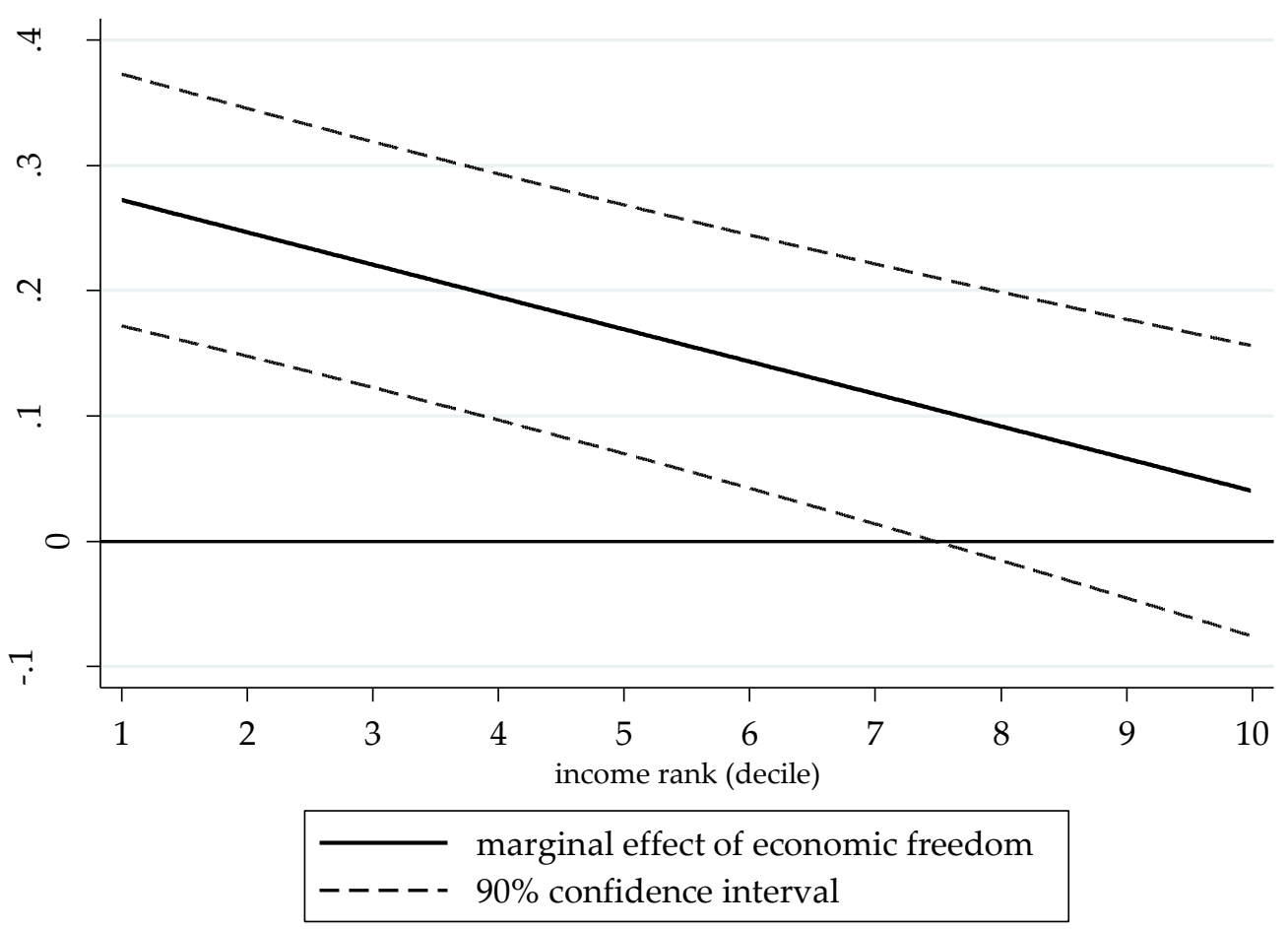

In addition to the point estimate line, we also display the $90 \%$ confidence interval. It can easily be seen here that a marginal increase of economic freedom at the $1^{\text {st }}$ income decile is associated with a comparatively higher life control perception of almost +0.3 points. The effect becomes weaker the further an individual moves up the income ladder. At the $8^{\text {th }}$ decile the effect is still positive, but it ceases to be significant at conventional levels. We replicated the whole analysis using income decile and income quintile dummies, finding very similar results (not shown): While the effect of increased economic freedom on life control is relatively strong at lower income deciles (quintiles), it disappears at high levels of income.

Turning to the high income countries in equations (3) and (4) of Table 2, the pattern is very similar (see also Figure 3 below) to the full sample. The only notable difference is that the marginal positive impact of economic freedom does not cease to be significant for the highest income category, even though it is much smaller than for the lowest. So even if an individual already encounters him or herself in the top part of the income distribution, the relative gain in life control from more economic freedom is still positive, despite the increase in competition that this will bring about. Nonetheless, relatively poor individuals seem to benefit much more from positive marginal changes in economic freedom, demonstrating the sizable life control effect of increased opportunities for the relatively poor.

For the group of poor countries in equation (5), marginal effects of higher freedom are always positive for all income groups, but disappear when we include the time period dummies. While we expected this to be the case for the higher income deciles, it is somewhat surprising that coefficients are never significant at a $10 \%$ confidence level, even for the lowest income groups (see Figure 4 below). To some degree, this finding reflects the problem of the time dummies mentioned above. What it further shows, though, is that marginal increases in economic freedom cannot immediately compensate the poor in developing countries, when they are already constrained by the economic and social hardships of absolute poverty. Increased economic 
possibilities are therefore of very little service to the poor, when other restrictions, such as in education, probably keep them from reaping those benefits.

Figure 3: Marginal effect of economic freedom (high income countries)

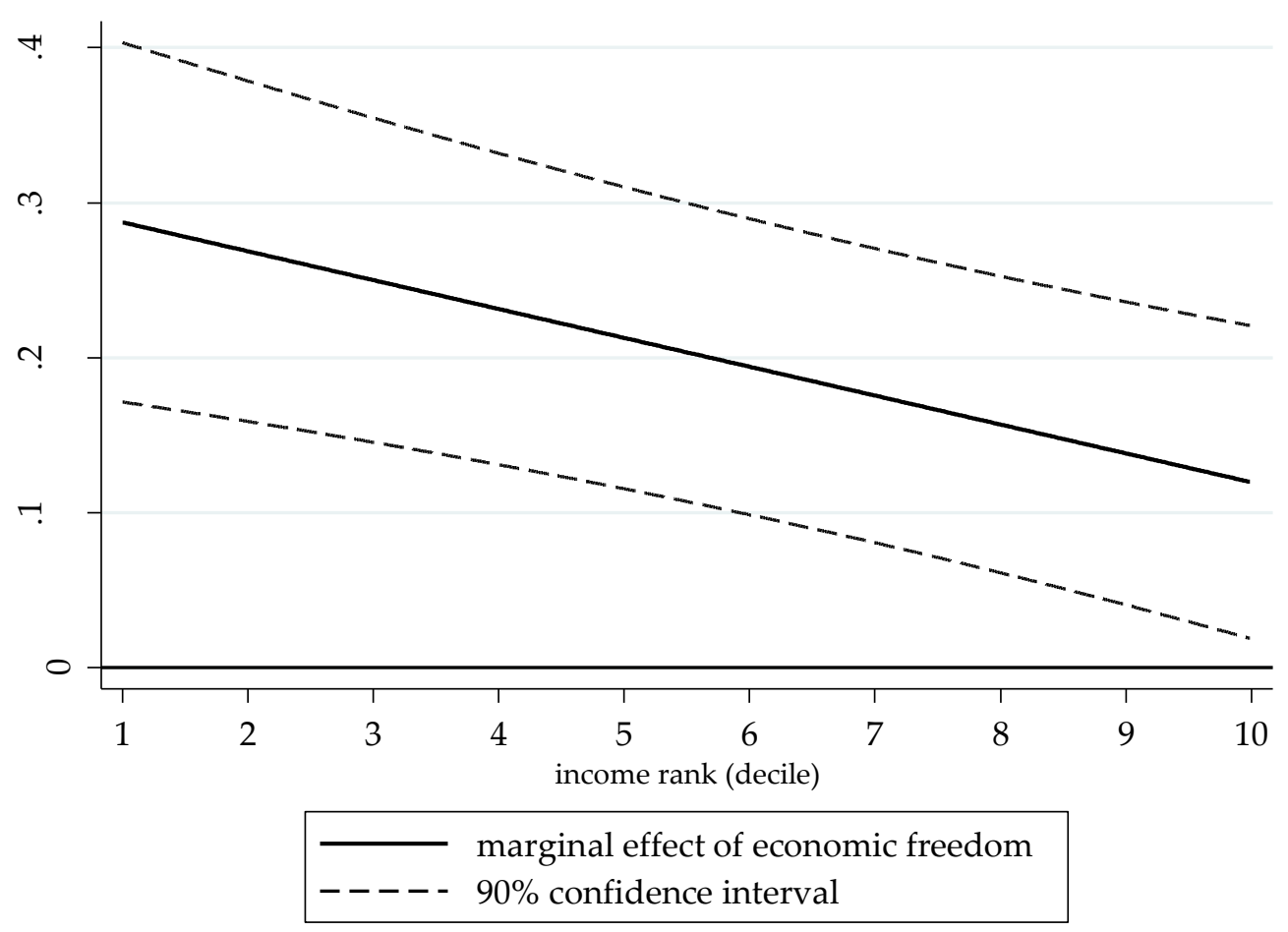

Figure 4: Marginal effect of economic freedom (low income countries)

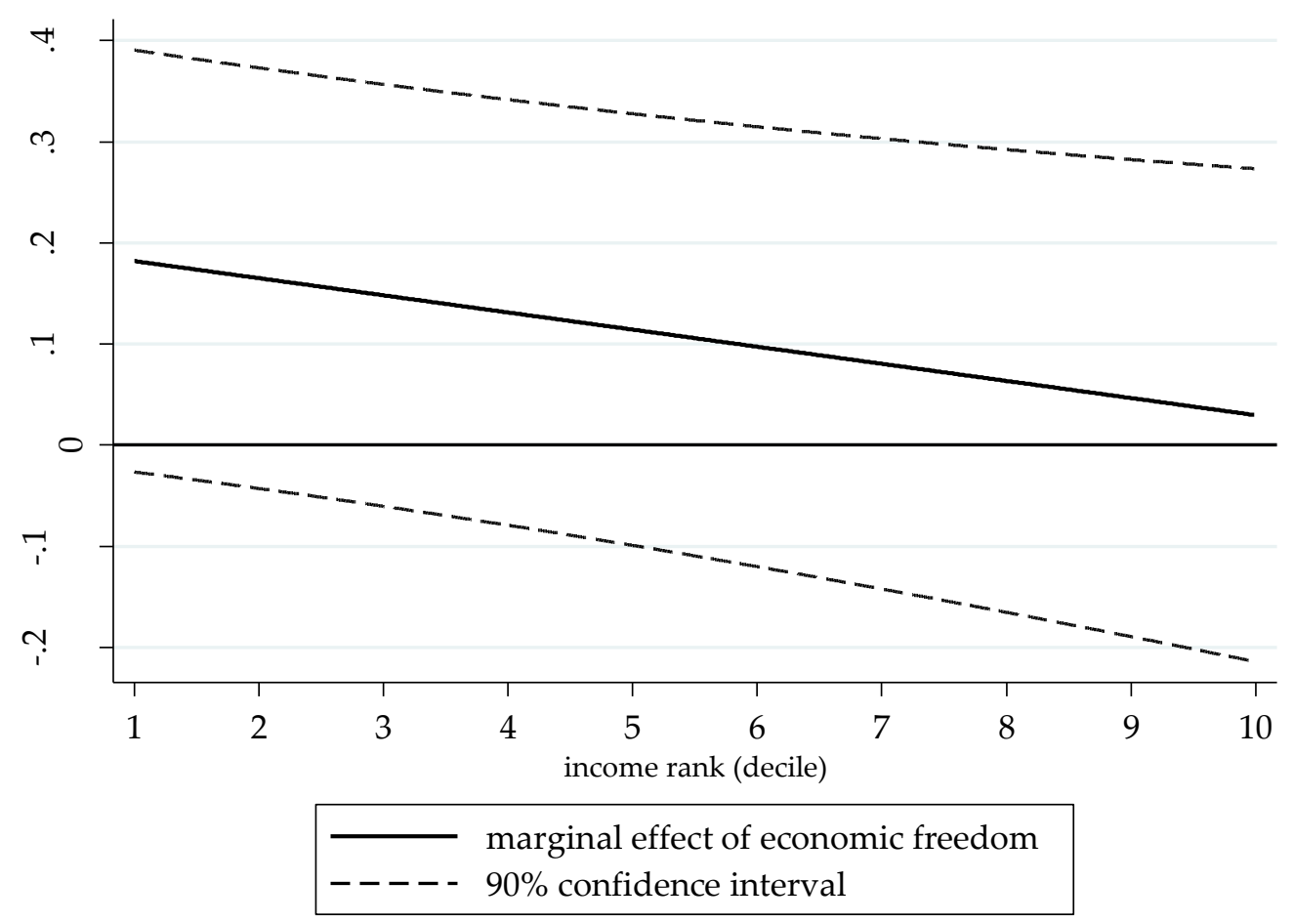


The results from Table 2 are quite instructive, as they seem to suggest that members of lowincome groups in developed countries indeed derive relatively more life control from the presence of economic freedom, as compared to members of high-income groups. Where regulation and market entry barriers are diminished, as represented by a high degree of economic freedom, life control perceptions of relatively poor people are increased, while relatively rich people are not negatively affected. As a consequence, the overall effect appears to be driven by a positive impact of economic freedom on lower income households. In turn, members of low-income groups in developing countries do not seem to derive relatively more life control from the presence of economic freedom, as compared to members of high-income groups. Diminishing regulation and market entry barriers do not benefit them in terms of life control, probably because other well-known socioeconomic restrictions of poverty keep them from reaping the immediate benefits.

The potential caveat with this last investigation is that we cannot really exclude an endogenous relationship between relative income and perceived life control of our survey respondents. Previous research has indicated that individuals with a high internal locus of control are more enterprising and therefore are also more likely to succeed in the business world (e.g. Hansemark, 2003). If this is the case, we are simply relating the socioeconomic status of our individual respondents to the underlying personality aspect that drives their economic success in the first place. Surely, it is difficult to speak of a causal effect under these circumstances.

Potentially, this problem could be remedied by employing an instrumental variable approach for relative income, which would take care of any possible endogeneity concerns. Still, the success of this strategy crucially depends on the quality of the respective excluded instruments for income rank, and these are somewhat hard to come by. While we tried to do this and could confirm the OLS results with a Two-Stage-Least-Squares analysis, we want to be careful not to over-emphasize the IV-exercise, due to the general doubts related to finding good and exogenous instruments. ${ }^{7}$

Generally speaking, an investigation such as this one can never really distinguish between causes and outcomes of individual personality traits, where these are all potential indicators of certain character groups. For example, it is perfectly possible that individuals with a higher life control are on average also those with higher social trust, higher income, etc., and vice versa. In this case, we are always relating different personality aspects to one another. Still, this does not affect the beneficial aspect of changes in economic freedom for life control, as all inhabitants of one country consume the same level of economic freedom, disregarding their individual personality. At the least, what we might be finding with our interaction terms is simply that more entrepreneurial characters are also better able to reap the benefits of higher marginal economic freedom, which is by no means a counterintuitive result.

\section{Conclusions}

The individual and societal determinants of happiness have been investigated intensively in recent years and relatively new findings indicate that one important correlate is the degree to which people feel they are in control of their own lives. In turn, the economic sources of life control are only insignificantly established in the current literature, despite the fact that Bavetta

\footnotetext{
${ }^{7}$ Our IV approach employed WVS/EVS information on respondents with a full-time job and no children. It can be assumed that both questions are directly related to individual income, but their direct relation to life control is, at least, ambiguous. Econometrically, the analysis confirmed the statistical validity and reliability of our excluded instruments, confirming also all of our previous results. These are not shown, but available in a previous Working Paper version of this paper, available on request.
} 
and Navarra (2011) find economic freedom and locus of control complement each other in the determination of happiness. Verme (2009) also claims that locus of control affects how people evaluate freedom of choice. Following Buchanan (2005), we try to find out if economic institutions that are built on the principle of free choice are also drivers of individual life control perceptions.

Employing individual data from the latest version of the World Value Survey (WVS), covering the period from 1981 to 2014, we find that living in a country with high overall economic freedom is a major determinant of feeling in control of one's own life. Interestingly, the effect is very similar for individuals in high- and low-income countries, while the impact of democracy is completely negligible in both cases. Interacting relative income with economic freedom, we further find that it is by far the lower income groups that derive the biggest life control from living in a country with comparatively high economic freedom, even though this only holds for countries that are economically developed.

We speculate that the strong relationship between economic freedom and life control at low income levels in developed economies is likely to be driven by people with an intrinsically entrepreneurial character. Previous research has linked entrepreneurs to a high internal locus of control, and these individuals are likely to see their life control increased when conditions of economic freedom prevail (e.g. McMullen et al. 2008). In this context, economic freedom probably acts as a kind of compensation mechanism vis-à-vis income: Low income earners are comparatively better compensated by the presence of economic freedom, which gives them the possibility to exercise free choice in the market. For high-income earners, this effect is much less important, as their income already gives them the access to more choices. From the standpoint of life control, economic freedom policies are therefore a real redistribution mechanism that relatively benefits low-income earners through enhanced free choice.

In the case of developing countries, it seems that there are additional barriers that make it impossible for low-income earners to reap the life control benefits of enhanced opportunities, at least in the short run. The extreme restrictions of absolute poverty leave these people without the ability to use new possibilities, which is a likely outcome of the very deficient education systems and highly restrictive informal institutions that these countries often have. Overcoming these restrictions will therefore be a major challenge for improving life control opportunities for some of the least well-off inhabitants of the planet.

\section{Acknowledgments}

We thank Christian Bjørnskov, Rosemarie Fike, and other participants of the "Institutions and Well-Being" session at the 2015 Public Choice Society meeting in San Antonio, TX for their helpful comments on an earlier version of the paper. An anonymous reviewer has provided further valuable feedback.

\section{Authors}

Hans Pitlik

Austrian Institute of Economic Research (WIFO)

hans.pitlik@wifo.ac.at

Martin Rode

Universidad de Navarra

\section{Publishing Timeline}

Received 1 January 2015

Accepted 31 August 2015 
Published 14 May 2016

\section{References}

April, K.A., Dharani, B., Peters, K., 2012. Impact of locus of control expectancy on level of well-being. Review of European Studies 4, 124-137. http://dx.doi.org/10.5539/res.v4n2p124

Bavetta, S., Navarra, P., 2011. Economic freedom and the pursuit of happiness. In: Miller, T., Holmes, K., (eds.) 2011 Index of Economic Freedom. Washington DC: Heritage Foundation, 61-68.

Bennett, D.L., \& Nikolaev, B., 2015. On the ambiguous economic freedom-inequality relationship. Social Science Research Network. http://ssrn.com/abstract $=2467222$

Berggren, N., 1999. Economic freedom and equality: Friends or foes? Public Choice 100, 203-223. http://dx.doi.org/10.1023/A:1018343912743

Berggren, N., 2003. The benefits of economic freedom. A survey. The Independent Review 8, 193-211.

Berggren, N., Jordahl, H., 2006. Free to trust: Economic freedom and social capital. Kyklos 59, 141-169. http://dx.doi.org/10.1111/j.1467-6435.2006.00324.x

Berggren, N., Nilsson, T., 2013. Does economic freedom foster tolerance? Kyklos 66, 177-207. http://dx.doi.org/10.1111/kykl.12017

Bergh, A., Nilsson, T., 2010. Do liberalization and globalization increase income inequality? European Journal of Political Economy 26, 488-505. http://dx.doi.org/10.1016/j.ejpoleco.2010.03.002

Bjørnskov, C., 2003. The happy few: Cross-country evidence on social capital and life satisfaction. Kyklos 56, 3-16. http://dx.doi.org/10.1111/1467-6435.00207

Buchanan, J.M., 2005. Afraid to be free: Dependency as desideratum. Public Choice 124, 19-31. http://dx.doi.org/10.1007/s11127-005-4743-2

Compton, R.A., Giedeman, D.C., Hoover, G.A., 2014. A distributional analysis of the benefits of economic freedom. European Journal of Political Economy 33, 121-133. http://dx.doi.org/10.1016/j.ejpoleco.2013.12.001

De Haan, J., Lundström, S., Sturm, J.-E., 2006. Market-oriented institutions and policies and economic growth: A critical survey. Journal of Economic Surveys 20, 157-191. http://dx.doi.org/10.1111/j.0950$\underline{0804.2006 .00278 . x}$

Dolan, P., Peasgood, T., White, M., 2008. Do we really know what makes us happy? A review of the economic literature on the factors associated with subjective well-being. Journal of Economic Psychology 29, 94-122. http://dx.doi.org/10.1016/j.joep.2007.09.001

Doucouliagos, C., Ulubasoglu, M., 2006. Economic freedom and economic growth: What difference does specification make? European Journal of Political Economy 22, 60-81. http://dx.doi.org/10.1016/j.ejpoleco.2005.06.003

Frey, B.S., 2008. Happiness: A revolution in economics. Cambridge: MIT Press. http://dx.doi.org/10.7551/mitpress/9780262062770.001.0001

Gehring, K., 2013. Who benefits from economic freedom? Unraveling the effect of economic freedom on subjective well-being. World Development 50, 74-90.

http://dx.doi.org/10.1016/j.worlddev.2013.05.003

Gwartney, J., Lawson, R., Hall, J., 2014. Economic Freedom of the World. 2014 Annual Report. Economic Freedom Network, Vancouver BC.

Hansemark, O.C., 2003. Need for achievement, locus of control and the prediction of business start-ups: A longitudinal study. Journal of Economic Psychology 24, 301-319. http://dx.doi.org/10.1016/S0167$\underline{4870(02) 00188-5}$

Inglehart, R., Foa, R., Peterson, C., Welzel, C., 2008. Development, freedom, and rising happiness. A global perspective 1981-2007. Perspectives on Psychological Science 3, 246-285.

Kouba, L., Pitlik, H., 2014. I wanna live my life: Locus of control and support for the welfare state. MENDELU Working Papers in Business and Economics 46/2014

McMullen, J., Bagby, D., Palich, L., 2008. Economic freedom and the motivation to engage in entrepreneurial action. Entrepreneurship Theory and Practice 32, 875-896. http://dx.doi.org/10.1111/j.1540-6520.2008.00260.x 
Moulton, B., 1990. An illustration of a pitfall in estimating the effects of aggregate variables in micro units. Review of Economics and Statistics 72, 334-338. http://dx.doi.org/10.2307/2109724

Ovaska, T., Takashima, R., 2006. Economic policy and the level of self-perceived well-being: An international comparison. The Journal of Socio-Economics 35, 308-325. http://dx.doi.org/10.1016/j.socec.2005.11.054

Pitlik, H., 2002. The path of liberalization and economic growth. Kyklos 55, 57-80. http://dx.doi.org/10.1111/1467-6435.00177

Rode, M., 2013. Do good institutions make citizens happy, or do happy citizens build better institutions? Journal of Happiness Studies 14, 1479-1505. http://dx.doi.org/10.1007/s10902-012-9391-x

Rode, M., Coll, S., 2012. Economic freedom and growth. Which policies matter the most? Constitutional Political Economy 23, 95-133. http://dx.doi.org/10.1007/s10602-011-9116-x

Rode, M., Gwartney, J.D., 2012. Does democratization facilitate economic liberalization? European Journal of Political Economy 28, 607-619. http://dx.doi.org/10.1016/j.ejpoleco.2012.07.001

Rotter, J.B., 1966. Generalized expectancies for internal versus external control of reinforcement. Psychological Monographs: General and Applied 80, 1-28. http://dx.doi.org/10.1037/h0092976

Schwartz, B., 2000. Self-determination: The tyranny of freedom. American Psychologist 55, 79-88. http://dx.doi.org/10.1037/0003-066X.55.1.79

Schwartz, B., 2004. The Paradox of Choice: Why More Is Less, New York: Ecco.

Verme, P., 2009. Happiness, freedom and control. Journal of Economic Behavior \& Organization 71, 146161. http://dx.doi.org/10.1016/j.jebo.2009.04.008

Welzel, C., 2013. Freedom rising: Human empowerment and the quest for emancipation, New York: Cambridge University Press. http://dx.doi.org/10.1017/CBO9781139540919

World Value Survey, 2014. European and world value surveys six-wave integrated data file, 1981-2014. The European Values Study Foundation and World Value Survey Association.

http://www.worldvaluessurvey.org 


\section{Appendices}

Table A1. Summary statistics

\begin{tabular}{lccccc}
\hline Variable & Obs & Mean & Std. Dev. & Min & Max \\
\hline individual & & & & & \\
lifecontrol & 262960 & 6.900494 & 2.33929 & 1 & 10 \\
incomedecile & 262960 & 4.843132 & 2.440296 & 1 & 10 \\
socialtrust & 262960 & .29784 & .4573097 & 0 & 1 \\
religiosity & 262960 & .6946418 & .4605599 & 0 & 1 \\
female & 262960 & .516706 & .4997218 & 0 & 1 \\
age1530 & 262960 & .3024224 & .4593081 & 0 & 1 \\
age60plus & 262960 & .1692539 & .3749767 & 0 & 1 \\
goodhealth & 262960 & .6728514 & .4691729 & 0 & 1 \\
selfemployed & 262960 & .1049475 & .3064864 & 0 & 1 \\
unemployed & 262960 & .0754411 & .2641023 & 0 & 1 \\
fulltime & 262960 & .3811606 & .4856728 & 0 & 1 \\
marriedtog r & 262591 & .635593 & .4812644 & 0 & 1 \\
separated & 262362 & .1255403 & .3313312 & 0 & 1 \\
macro & & & & & \\
EFW & 183 & 6.754481 & 1.061772 & 3.39 & 8.59 \\
GDPPC & 183 & 9.309219 & 1.045999 & 5.436913 & 10.85212 \\
DEMPOL & 183 & 7.850638 & 2.906905 & 0 & 10 \\
\hline
\end{tabular}


Table A2. Country sample

\begin{tabular}{ll}
\hline High income sample & Lower income sample \\
\hline Australia & Albania \\
Austria & Argentina \\
Belgium & Bangladesh \\
Bulgaria & Brazil \\
Canada & Chile \\
Croatia & China \\
Cyprus & Colombia \\
Czech Republic & Dominican Republic \\
Denmark & Egypt \\
Estonia & El Salvador \\
Finland & Ghana \\
France & Guatemala \\
Germany & Indonesia \\
Greece & India \\
Hungary & Iran \\
Iceland & Jordan \\
Ireland & Malaysia \\
Italy & Mali \\
Japan & Mexico \\
Korea & Morocco \\
Latvia & Nigeria \\
Lithuania & Pakistan \\
Luxembourg & Peru \\
Malta & Philippines \\
Netherlands & Russia \\
New Zealand & Rwanda \\
Norway & South Africa \\
Poland & Thailand \\
Portugal & Trinidad and Tobago \\
Romania & Turkey \\
Singapore & Tanzania \\
Slovak Republic & Uganda \\
Slovenia & Ukraine \\
Spain & Venezuela \\
Sweden & Zambia \\
Taitzerland & United Kingdom \\
United States of America & \\
\hline
\end{tabular}

